\begin{tabular}{ll|l} 
Case Reports in & \multicolumn{2}{c}{ Case Rep Gastroenterol 2013;7:511-515 } \\
\cline { 2 - 3 } Gastroenterology & $\begin{array}{l}\text { DOI: 10.1159/000357589 } \\
\text { Publisnea onine: December 12, 2013 }\end{array}$ & $\begin{array}{l}\text { ○ 2013 S. Karger AG, Basel } \\
\text { www.karger.com/crg }\end{array}$ \\
\hline & $\begin{array}{l}\text { This is an Open Access article licensed under the terms of the Creative Commons } \\
\text { Attribution-NonCommercial 3.0 Unported license (CC BY-NC) (www.karger.com/OA- } \\
\text { license), applicable to the online version of the article only. Distribution permitted for non- } \\
\text { commercial purposes only. }\end{array}$
\end{tabular}

\title{
Primary Systemic Amyloidosis with Extensive Gastrointestinal Involvement
}

\author{
V. Gaduputi K. Badipatla H. Patel H. Tariq A. Ihimoyan \\ Bronx-Lebanon Hospital Center, New York, N.Y., USA
}

\section{Key Words}

Primary amyloidosis - Gastrointestinal amyloidosis - Primary systemic light-chain amyloidosis . Light-chain amyloidosis - Gastrointestinal involvement in primary systemic amyloidosis

\begin{abstract}
We report this case of a 42-year-old woman who presented with a debilitating illness manifested by intractable nausea, vomiting, diarrhea and unchecked weight loss. The patient had multisystem involvement that presented as anemia, abnormal liver function tests and progressively deteriorating renal function necessitating dialysis. She was found to be profoundly hypoalbuminemic secondary to malabsorptive and protein-losing enteropathy in tandem with nephrotic range proteinuria. Intolerance to enteral feeding led the patient to be dependent on parenteral nutrition. Serum immunofixation revealed IgG lambda monoclonal protein. The patient underwent endoscopic evaluation with biopsies taken from the gastrointestinal tract that confirmed the diagnosis of primary systemic light-chain amyloidosis. A subsequent bone marrow biopsy revealed normocellular bone marrow with deposition of amyloid. The patient was not considered for autologous stem cell transplantation as the outcomes in patients with multisystem involvement are often poor, with a high mortality risk. Diffuse primary systemic light-chain amyloidosis involving the gastrointestinal tract is a rare entity and is to be considered among differentials in patients presenting with unexplained malabsorptive symptoms.

(C) 2013 S. Karger AG, Basel
\end{abstract}

\section{Introduction}

Amyloidosis is an umbrella term encompassing disorders characterized by deposition of fibrils consisting of low-molecular subunits of misfolded normal serum proteins and

Dr. Hassan Tariq

Bronx-Lebanon Hospital Center

1650 Selwyn Ave, Suit \#10C

Bronx 10457, New York City, NY (USA)

E-Mail htariq@bronxleb.org 
Gaduputi et al.: Primary Systemic Amyloidosis with Extensive Gastrointestinal Involvement

typically arranged in an antiparallel $\beta$-pleated sheet configuration [1]. Primary systemic light-chain amyloidosis is the most common cause of amyloidosis in the western hemisphere [2]. However, primary systemic light-chain amyloidosis is still a rare entity with an estimated annual incidence of only about 3,000 cases in the United States [3]. Biopsy-proven primary systemic light-chain amyloidosis involving the gastrointestinal tract is even rarer [4]. A retrospective review of data collected from patients with all types of amyloidosis showed that only 3.2\% had biopsy-proven amyloid involvement of the gastrointestinal tract [5]. The mean age of presentation for primary systemic light-chain amyloidosis is usually in the sixth to seventh decade of life, as evidenced by multiple retrospective studies [5-8]. Gastrointestinal involvement in light-chain amyloidosis is defined by the presence of gastrointestinal symptoms with direct biopsy verification of amyloid deposition. The most common symptoms of gastrointestinal amyloidosis include abdominal pain, esophageal reflux, constipation and nausea. The pathophysiology of other symptoms, such as diarrhea, weight loss and early satiety, is much more complex and may include other mechanisms such as autonomic neuropathy, small bowel bacterial overgrowth or cardiac cachexia [5]. We report a rare case of biopsy-proven primary light-chain amyloidosis of the gastrointestinal tract in a much younger woman.

\section{Case Report}

A 42-year-old African American woman, born and raised in the United States, presented to the hospital with diarrhea, nausea and intractable vomiting with inability to tolerate oral feeding for 1 week. The patient had multiple prior visits to another institution with similar complaints, where a provisional diagnosis of gastroesophageal reflux disease was made from esophagogastroduodenoscopy. Upon further enquiry, she reported these symptoms to have started more than a year prior to the index presentation. Physical examination at the time of admission revealed a cachectic and disoriented young woman. Other pertinent positive findings of physical examination included hepatomegaly $(20 \mathrm{~cm})$ with ascites and bilateral pitting type of pedal edema.

An initial set of laboratory studies showed microcytic, hypochromic anemia (hemoglobin $8.4 \mathrm{~g} / \mathrm{dl}$ ), abnormal coagulation parameters (PT $17.1 \mathrm{~s}$, aPTT $37.1 \mathrm{~s}$ ), renal dysfunction (BUN $37 \mathrm{mg} / \mathrm{dl}$, serum creatinine $2.0 \mathrm{mg} / \mathrm{dl}$ ), abnormal liver enzymes (alanine transaminase $51 \mathrm{IU} / \mathrm{l}$, aspartate transaminase $77 \mathrm{IU} / \mathrm{l}$, markedly elevated alkaline phosphatase of 1,655 IU/l with normal bilirubin levels), profound serum hypoalbuminemia $(1.5 \mathrm{gm} / \mathrm{dl})$ and nephrotic range of proteinuria (urine dipstick protein assay showed 5+ proteinuria and the spot urine protein/creatinine ratio was 5.7). Additional work-up done for evaluation of abnormal liver enzymes including viral hepatitis panels (hepatitis A, B and C), ANA, anti-smooth muscle antibody, anti-liver kidney microsomal antibodies and antimitochondrial antibody was negative. Serum immunofixation revealed IgG lambda monoclonal protein. Urine immunofixation was negative. An echocardiogram revealed concentric left ventricular hypertrophy with a normal ejection fraction of $78 \%$. A computed tomography scan of the abdomen showed pelvic ascites with mild, diffuse bowel wall thickening.

The patient's hospital course was marked by the persistence of diarrhea with minimal response to presumptive therapy with antibiotics (intravenous metronidazole and oral vancomycin). Stool work-up done for diarrhea revealed no infectious etiology. The patient had deteriorating renal function necessitating renal replacement therapy. She had a selflimited episode of hematemesis. 
Gaduputi et al.: Primary Systemic Amyloidosis with Extensive Gastrointestinal Involvement

The patient underwent esophagogastroduodenoscopy and colonoscopy that revealed no gross mucosal lesions. Multiple random biopsies were taken from the stomach, duodenum, terminal ileum, colon and rectum. Biopsy results showed eosinophilic, acellular, globular deposits in the lamina propria and submucosa which stained positively with Congo, consistent with amyloidosis (fig. 1). A subsequent bone marrow biopsy revealed normocellular bone marrow with trilineage maturation and diffuse extracellular eosinophilic, amorphous material consistent with amyloidosis (fig. 2). A definitive diagnosis of primary systemic light-chain amyloidosis with gastrointestinal tract involvement was made. The patient was not considered for autologous stem cell transplantation, since the outcomes of autologous stem cell transplant in patients with multisystem involvement are often poor and fraught with a high mortality risk. She was subsequently referred to another institution for further management.

\section{Discussion}

Our patient presented with multiple symptoms that are prototypical of extensive gastrointestinal involvement from primary systemic amyloidosis. It has been reported that only about $8 \%$ of patients have biopsy-proven amyloidosis in the gastrointestinal tract and only about $1 \%$ become symptomatic from gastric involvement [4]. The spectrum of symptoms from gastrointestinal amyloidosis is wide, including gastroesophageal reflux disease-like symptoms, nausea and abdominal pain. Symptoms of malabsorption like diarrhea, weight loss and early satiety often result from autonomic neuropathy and small bowel bacterial overgrowth $[7,9,10]$. It has been postulated that severe diarrhea associated with gastrointestinal amyloidosis could also be a result of rapid intestinal transit [11]. The underlying pathology for most of these symptoms is amyloid infiltration and replacement of the intestinal smooth muscle causing dysmotility $[12,13]$, which in extreme cases can even present as pseudo-obstruction $[8,12,14,15]$. Ischemia secondary to vascular infiltration or depletion of ganglion cells has also been noted.

Another constellation of symptoms includes that of gastrointestinal hemorrhage manifesting with hematemesis as seen in our patient, hematochezia and even gastric perforation [16-18]. Gastrointestinal hemorrhage could be seen in up to $45 \%$ of patients with amyloidosis, likely secondary to ischemia, ulceration or generalized mucosal oozing [19]. The finding of a normal endoscopic picture in our patient is unusual, as endoscopic abnormalities such as ulceration and submucosal hematomas were found in nearly $75 \%$ of patients with gastrointestinal amyloidosis [20]. The radiological features are varied as well, ranging from subtle bowel wall thickening as seen in our patient (fig. 1) to multiple cystic submucosal masses of the stomach [21], intestinal pseudo-obstruction and thumbprinting on enteroclysis [8].

Primary systemic light-chain amyloidosis should be distinguished from other diseases related to deposition of monoclonal light chains, such as noncongophilic light chain deposition disease, and from other forms of systemic amyloidosis. Even as findings of extracellular amorphous material, which is moderately positive for periodic acid-Schiff (PAS) and strongly congophilic, is pathognomonic of amyloidosis, it has been reported that noncalcified psammoma bodies can present as PAS-positive extracellular eosinophilic infiltrates as well [22]. Lipoid proteinosis is another entity characterized by multisystem involvement from deposition of PAS-positive hyaline material in the skin, mucous membranes and internal organs, described in the literature as a disorder with multisystem involvement [23]. 
Gaduputi et al.: Primary Systemic Amyloidosis with Extensive Gastrointestinal Involvement

Light-chain amyloidosis is a rare and potentially fatal disease that is most often underdiagnosed. Advances in diagnostic techniques along with use of cardiac biomarkers for staging and free light chains to gauge response have impacted the rates of diagnosis, morbidity and mortality of this disease. The management of primary light-chain amyloidosis is predominantly aimed at elimination of the pathologic plasma cells and thereby the circulating free light chain. This could lead to regression of amyloid deposits, improvement in organ function and offer survival benefit [2]. Autologous stem cell transplantation is an effective and rapid way of achieving clinical response, but only less than a quarter of all patients with primary systemic amyloidosis are candidates for this therapy [24]. Melphalan and dexamethasone regimen became the frontline therapy for patients ineligible for stem cell transplantation [25]. The management of amyloidosis often requires a multidisciplinary approach and close follow-up for long periods of time. This is especially true as it was noted that even in patients with prompt hematologic response, regression of organ damage often takes months to years [2].

\section{References}

1 Bhat A, Selmi C, Naguwa SM, Cheema GS, Gershwin ME: Currents concepts on the immunopathology of amyloidosis. Clin Rev Allergy Immunol 2010;38:97-106.

-2 Rosenzweig M, Landau H: Light chain (AL) amyloidosis: update on diagnosis and management. J Hematol Oncol 2011;4:47.

-3 Gertz MA, Lacy MQ, Dispenzieri A: Amyloidosis: recognition, confirmation, prognosis, and therapy. Mayo Clin Proc 1999;74:490-494.

4 Menke DM, Kyle RA, Fleming CR, Wolfe JT 3rd, Kurtin PJ, Oldenburg WA: Symptomatic gastric amyloidosis in patients with primary systemic amyloidosis. Mayo Clin Proc 1993;68:763-767.

-5 Cowan AJ, Skinner M, Seldin DC, Berk JL, Lichtenstein DR, O’Hara CJ, Doros G, Sanchorawala V: Amyloidosis of the gastrointestinal tract: a 13-year, single-center, referral experience. Haematologica 2013;98:141-146.

-6 Kyle RA, Linos A, Beard CM, Linke RP, Gertz MA, O'Fallon WM, Kurland LT: Incidence and natural history of primary systemic amyloidosis in Olmsted County, Minnesota, 1950 through 1989. Blood 1992;79:18171822.

7 Madsen LG, Gimsing P, Schiødt FV: Primary (AL) amyloidosis with gastrointestinal involvement. Scand J Gastroenterol 2009;44:708-711.

-8 Kala Z, Válek V, Kysela P: Amyloidosis of the small intestine. Eur J Radiol 2007;63:105-109.

-9 Sattianayagam PT, Hawkins PN, Gillmore JD: Systemic amyloidosis and the gastrointestinal tract. Nat Rev Gastroenterol Hepatol 2009;6:608-617.

10 Hayman SR, Lacy MQ, Kyle RA, Gertz MA: Primary systemic amyloidosis: a cause of malabsorption syndrome. Am J Med 2001;111:535-540.

11 Guirl MJ, Högenauer C, Santa Ana CA, Porter JL, Little KH, Stone MJ, Fordtran JS: Rapid intestinal transit as a primary cause of severe chronic diarrhea in patients with amyloidosis. Am J Gastroenterol 2003;98: 2219-2225.

12 Kyle RA, Gertz MA: Primary systemic amyloidosis: clinical and laboratory features in 474 cases. Semin Hematol 1995;32:45-59.

13 Tada S, Iida M, Yao T, Kitamoto T, Yao T, Fujishima M: Intestinal pseudo-obstruction in patients with amyloidosis: clinicopathologic differences between chemical types of amyloid protein. Gut 1993;34: 1412-1417.

14 Liapis K, Michelis FV, Delimpasi S, Karmiris T: Intestinal pseudo-obstruction associated with amyloidosis. Amyloid 2011;18:76-78.

15 Intestinal pseudo-obstruction. Br Med J 1973;1:64-65.

16 Kamata T, Suzuki H, Yoshinaga S, Nonaka S, Fukagawa T, Katai H, Taniguchi H, Kushima R, Oda I: Localized gastric amyloidosis differentiated histologically from scirrhous gastric cancer using endoscopic mucosal resection: a case report. J Med Case Rep 2012;6:231.

17 Wu D, Lou JY, Chen J, Fei L, Liu GJ, Shi XY, Lin HT: A case report of localized gastric amyloidosis. World J Gastroenterol 2003;9:2632-2634.

18 Deniz K, Sari I, Torun E, Patiroğlu TE: Localized gastric amyloidosis: a case report. Turk J Gastroenterol 2006;17:116-119.

19 Levy DJ, Franklin GO, Rosenthal WS: Gastrointestinal bleeding and amyloidosis. Am J Gastroenterol 1982;77: 422-426. 
Gaduputi et al.: Primary Systemic Amyloidosis with Extensive Gastrointestinal Involvement

20 James DG, Zuckerman GR, Sayuk GS, Wang HL, Prakash C: Clinical recognition of AL type amyloidosis of the luminal gastrointestinal tract. Clin Gastroenterol Hepatol 2007;5:582-588.

21 Kim SH, Han JK, Lee KH, Won HJ, Kim KW, Kim JS, Park CH, Choi BI: Abdominal amyloidosis: spectrum of radiological findings. Clin Radiol 2003;58:610-620.

22 Schneider NI, Bauernhofer T, Schöllnast H, Ott A, Langner C: Pancreatic adenocarcinoma with multiple eosinophilic extracellular deposits consistent with noncalcified psammoma bodies. Virchows Arch 2011;459:623-625.

23 Di Giandomenico S, Masi R, Cassandrini D, El-Hachem M, De Vito R, Bruno C, Santorelli FM: Lipoid proteinosis: case report and review of the literature. Acta Otorhinolaryngol Ital 2006;26:162-167.

24 Gertz MA, Lacy MQ, Dispenzieri A, Hayman SR, Kumar SK, Dingli D, Ansell SM, Gastineau DA, Inwards DJ, Johnston PB, Litzow MR, Micallef IN, Porrata LF, Leung N, Hogan WJ, Buadi FK: Autologous stem cell transplant for immunoglobulin light chain amyloidosis: a status report. Leuk Lymphoma 2010;51:21812187.

25 Gertz MA: How to manage primary amyloidosis. Leukemia 2012;26:191-198.

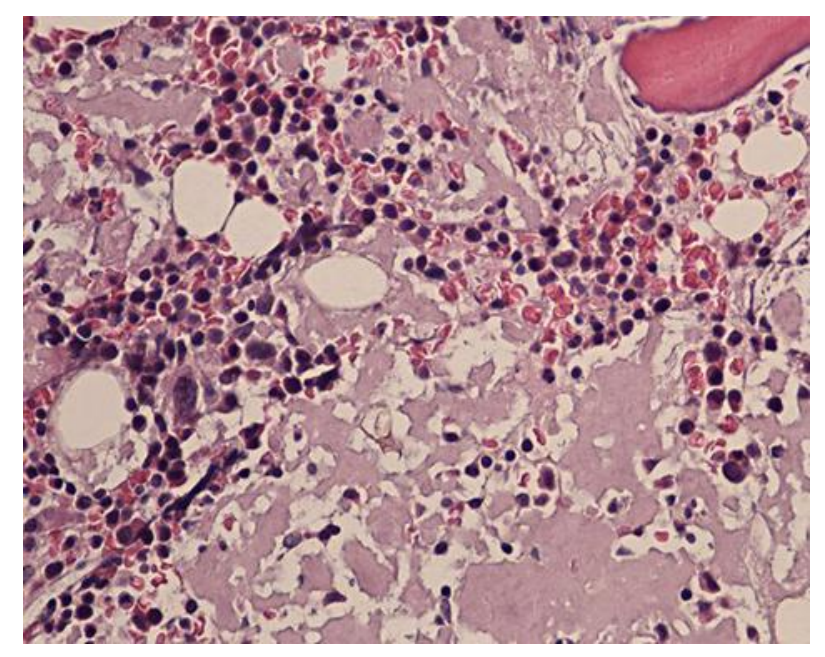

Fig. 1. Bone marrow biopsy (magnification: 40×) showing normocellular bone marrow with trilineage maturation and diffuse extracellular eosinophilic, amorphous material consistent with amyloidosis.

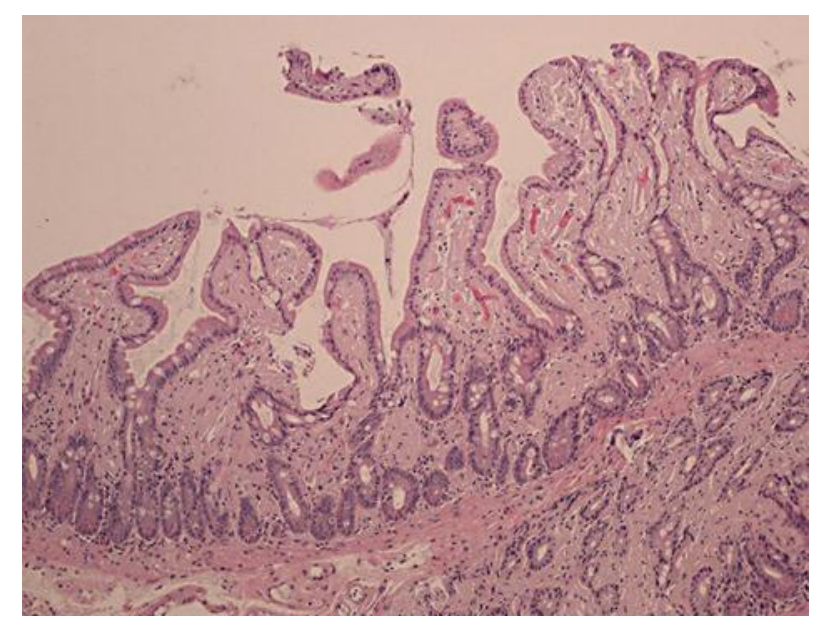

Fig. 2. Small bowel biopsy (magnification: 100x) showing eosinophilic, acellular, globular deposits in the lamina propria and submucosa which stained positively with Congo, consistent with amyloidosis. 